\section{A CONSTRUÇÃO DO CONHECIMENTO CIENTÍFICO NA ÁREA EDUCACIONAL}

\section{THE CONSTRUCTION OF SCIENTIFIC KNOWLEDGE IN THE EDUCATIONAL AREA}

Daniel de Jesus Silva ${ }^{1}$

\section{INTRODUÇÃO}

Ao discutir sobre o do processo de construção do conhecimento cientifico na educação, devemos pensar o papel do ensino e da pesquisa. Há procedimentos necessários para a produção de conhecimento científico na área educacional, critérios de proposição e validação de trabalhos científicos, as regras elementares para a construção de uma investigação cientifica e a sistemática para avaliação e divulgação de pesquisas nessa área do conhecimento.

$\mathrm{O}$ rigor empregado nos procedimentos legitimados para se investigar uma questão educacional é responsável por uma arquitetura teórico-conceitual com fins à uma produção teórica com potencial de aplicação prática e inovadora à educação. A partir do século XX que entendeu-se delegar à universidade não apenas o ensino, mas também a pesquisa como produção de conhecimento e, até mesmo, a extensão como serviço à sociedade. Dessa forma, a universidade está pautada no tripé: ensino, pesquisa e extensão, e esses não se excluem mutuamente, ao contrário, eles devem estar fortemente relacionados. Nesse propósito, o fazer ciência é uma atividade social, cuja produção está condicionada a fatores circunstanciais e contingenciais e é resultante da combinação de fatores econômicos e tecnológicos.

É possível admitir-se que, no momento, faz-se necessário pesquisas sobre os melhores métodos e técnicas para um ensino eficiente e dificilmente vai a universidade, produzir novos saberes se não atentar para o aprimoramento do ensino que não se reduz à simples transmissão do conhecimento. Nesse sentido, investigações em busca de uma perspectiva afirmativa para a formação de professores, sobretudo, professores-pesquisadores faz-se essencial.

\section{RESUMO}

A construção do conhecimento sobre educação abarca tanto a pesquisa como o ensino, sendo que estes constituem critérios elementares na composição da estrutura para o fazer Ciência. Este artigo analisará como o conhecimento científico é construído, com o foco em dois aspectos: A realidade e sua construção social, respaldado pela teorização de Berger e Luckmann (1985); e o olhar científico, embasado por Thomas S. Kuhn (2011), buscando aproximações com outros autores contemporâneos. Por fim, apresentará uma relação entre ensino e pesquisa educacional, atribuindo ao professor, seu lugar no cenário de debates teórico-conceituais e metodológicos, com fins, a não dicotomizar o ato de lecionar e o de pesquisar na área educacional, para favorecer a construção de conhecimentos que respondam questões latentes da educação.

Palavras Chave: Conhecimento científico; Educação; Pesquisa; Ensino.

\section{ABSTRACT}

The construction of knowledge about education encompasses both research and teaching, and these are basic criteria in the composition of the structure to do Science. This paper will analyze how scientific knowledge is constructed, with a focus on two aspects: Reality and its social construction, supported by the theorizing of Berger and Luckmann (1985); and the scientific perspective, based on Thomas S. Kuhn (2011), seeking approximations with other contemporary authors. Finally, it will present a relationship between teaching and educational research, assigning the teacher his place in the scenario of theoretical-conceptual and methodological debates, with purposes, not to dichotomize the act of teaching and research in the educational area, to favor the construction knowledge that answers latent issues of education.

Keywords: Scientific knowledge; Education; Search; Teaching.

Submetido em: 15 de mai. 2018

Aceito em: 15 de mar. 2019 
A preocupação com a desarticulação entre a formação de professores e a prática ao lecionar, é generalizada. Felix Klein, matemático alemão, por volta de 1908, apontava um significativo distanciamento entre a matemática dos cursos universitários de formação de professores e a matemática da escola básica.

"As reflexões de Klein, feitas há mais de cem anos, não são fruto de pesquisas em Educação Matemática, e se referem a um momento anterior à própria consolidação da área como um campo acadêmico" (Giraldo et al, 2018, p.02). No entanto, tais problemas persistem ao longo do tempo, em contextos culturais diversificados, revelando o quanto a formação de professores é um problema complexo e epistemológico, fazendo jus, às pesquisas nesse campo social, a educação.

\section{A REALIDADE E SUA CONS- TRUÇÃO SOCIAL NA PESQUISA EDUCACIONAL}

O plano analítico pensado pelos autores Berger e Luckmann (1985) ao transcorrer sobre $A$ construção social da realidade, foi uma "tentativa de desenvolver uma teoria sistemática da sociologia do conhecimento" para estimular a "discussão crítica e as pesquisas empíricas" (BERGER; LUCKMANN, 1985, p. 242), onde redefine como estudo de tudo aquilo que se considera conhecimento na sociedade, especialmente o conhecimento do senso comum que constitui a realidade cotidiana para o membro comum da sociedade. Os autores afirmam a precedência do conhecimento sobre os valores. Dessa forma, só há realidade quando há conhecimento, diante de interação num plano coletivo. Essas experiências resultam na construção do conhecimento.
A chamada "construção do conhecimento" não é totalmente livre e aleatória, ela deve corresponder a uma unidade de pensamento, a uma concordância, a um consenso universal. Não se pode imaginar que possa, cada um, "construir" o seu conhecimento de modo unilateral e independente sem vínculo com a comunidade científica e com o saber universal. De acordo Werneck (2006):

Considera-se como construção o ato de construir algo, e, como ato ou ação a terceira etapa do processo da vontade. Ante um objeto que mobilize o sujeito vão ocorrer três etapas: a deliberação, a decisão e por fim, a execução. A ação é entendida como um processo racional e livre decorrente da inteligência e da vontade. (WERNECK, 2006, p.175).

Neste caso não se trata de um ato como movimento involuntário do sujeito, e sim de ação resultante de motivação. Motivações diversas impelem a uma ação; esta por sua vez é diferente de interação, que se caracteriza pelo sentido das ações serem compartilhadas com mais pessoas. Dessa forma, há perceptível limitação entre ação individual e ação coletiva.

$\mathrm{Na}$ visão Weberiana (SANTOS, 2005), Ação ou ato social é uma conduta humana dotada de sentido, ou seja, de uma justificativa subjetivamente elaborada. Para a construção da realidade, a ação social é constituída de três momentos fundamentais: (1) motivação, que atribui determinado sentido, uma justificativa pessoal; (2) Ação, propriamente dita, as tomadas de atitudes; (3) resultado objetivo da ação, que pode convergir ou mesmo divergir com as motivações iniciais, pois não depende do sujeito individualmente e sim da interação com os outros, dessa forma a conclusão sem- pre será a partir de uma abordagem probabilística.

Considerando que o fazer científico gira em torno de ações, compreender o papel desempenhado pelo professor e pelos pesquisadores em educação na sociedade foi e tem sido uma questão para muitos, instigante. Diversos autores também demonstraram essa preocupação em seus trabalhos, sob diferentes perspectivas. Dessa forma, é necessário, primeiro, discutirmos aspectos que colaboram com tais construções na área educacional. É preciso compreender de que forma a realidade social é apreendida e construída, especialmente, nesse novo cenário onde os professores, têm um papel mais ativo e colaborativo, impondo novos desafios, elucidando que seus locais de atuação profissional são espaços de produção de saberes, onde hoje cada mais se vê o professorpesquisador.

Berger e Luckmann (1985, p. 11) aponta que a construção da realidade trata-se de um fenômeno social, ou seja, "a realidade é construída socialmente" e a sociologia do conhecimento tem a tarefa de analisar de que forma esse fato acontece. Nesse sentido, o entendimento é de que a sociologia do conhecimento tem por finalidade analisar as relações que existem entre o pensamento humano e o contexto por meio do qual esse pensamento surge, tendo por fim a tarefa de:

\footnotetext{
Ocupar-se com o que os homens "conhecem" como "realidade" em sua vida cotidiana, vida não teórica ou pré-teórica. Em outras palavras, o "conhecimento" do senso comum, e não das "ideias", deve ser o foco central da sociologia do conhecimento. É precisamente este "conhecimento" que constitui o tecido de significados sem o qual nenhuma sociedade poderia existir.
} 
[...] A sociologia do conhecimento, portanto, deve tratar da construção social da realidade (BERGER; LUCKMANN, 1985, p. 29-30).

\section{Berger e Luckmann (1985)} fazem a análise da vida cotidiana sob o aspecto da fenomenologia. A realidade é constituída pelo sentido de nossas experiências, ou seja, está ligada ao conceito de tipificação, que compreende a biografia e o acervo de conhecimento que o ser humano possui. E é a partir dessas informações que cada pessoa age tipicamente nas suas relações diárias. Considerando que há um motivação que está por trás do ato de agir, e por estar relacionada com a realidade social, não existe uma única forma de agir.

Se tomarmos como base a ação dos professores, podemos dizer que é autoconsciente no momento em que eles têm por finalidade refletirem ou até mesmo registrar determinados episódios de suas práticas de sala de aula, que lhes causam inquietações. E é evidente que cada um deles o fez por diferentes propósitos: autoavaliação, compartilhar experiência com outros colegas de profissão, registrar uma determinada ação para posterior análise, pensar nova estratégia de ensino, etc. $\mathrm{O}$ fato dessas inquietações ganharem grandes dimensões implica em uma série de ações desenvolvidas em pesquisa empíricas com foco na construção do conhecimento cientifico sobre a educação.

Embora as motivações são pessoais, na forma de tentar superar obstáculos, elaborar projetos e desenvolverem pesquisas acadêmicas, as decisões de um professor-pesquisador não estão embasadas apenas nos seus próprios pensamentos, pois existe um intercâmbio social. Todos agem com base nos conhecimentos outrora construídos, na própria história biográfica e também na interação social com outros. Dessa forma, a realidade da vida cotidiana "apresenta-se a mim como um mundo intersubjetivo, um mundo de que participo juntamente com outros homens" (BERGER; LUCKMAN, 1985, p. 40).

Essa interação pauta no relacionamento social onde o contato face a face é a principal forma de interagir, em que duas consciências se apreendem mutuamente através de uma reciprocidade de expressões subjectivas. No meio educacional, a presença do outro é uma realidade que se impõe por si mesma e é continuamente acessível a uma consciência. E o relacionamento consiste em esquema tipificado: como professor/aluno, pesquisador/orientador, pesquisador/sujeito.

Berger e Luckmann (1985) consideram que as relações face a face estão ligadas a realidade da vida diária, isso quer dizer que "a realidade da vida cotidiana está organizada em torno do 'aqui' de meu corpo e do 'agora' do meu presente. Este 'aqui e agora' é o foco da minha atenção à realidade da vida cotidiana". No entanto, os mesmos autores afirmam que a realidade não se esgota no "aqui $\mathrm{e}$ agora”, pois a vida cotidiana é experimentada,

Em diferentes graus de aproximação e distância, espacial e temporalmente. A mais próxima de mim é a zona da vida cotidiana diretamente acessível à minha manipulação corporal. Esta zona contém o mundo que se acha ao meu alcance, o mundo em que atuo a fim de modificar a realidade dele, ou o mundo em que trabalho. [...] Sei, evidentemente, que a realidade da vida cotidiana contém zonas que não me são acessíveis desta maneira. Mas, ou não tenho interesse pragmático nessas zonas ou meu interesse nelas é indireto, na medida em que po- dem ser potencialmente zonas manipuláveis por mim. Tipicamente meu interesse nas zonas distantes é menos intenso e certamente menos urgente. (BERGER; LUCKMANN, 1985, p. 39).

O local de atuação docente sem dúvida configura a zona de experiência mais acessível, urgente, onde o professor pode modificar, por isso vivem em expectativa da realidade. No entanto, a realidade está sujeita a mudanças, de acordo com as atuações dos professores no cenário e com a conjuntura na qual estão inseridos. O cenário educacional, como qualquer outro, é dinâmico, de ação e reação. Nesse contexto o que diferenciará um professor "comum" de um professorpesquisador, são suas visões pautadas nas dúvidas. A visão do homem "comum" está ligado nas certezas, numa zona de estabilidade, já a do ser cientista pauta na falta de certeza. Dessa forma, o docente que se propõe a pesquisar deve aguçar a priori duas técnicas antropológicas: a observação e o estranhamento. Estranhamento é não achar normal, espantar-se, incomodarse com algo, identificar um problema no seu cenário educacional.

Normalmente a consciência está repleta de prenoções sobre a realidade, provenientes do senso comum. Ele é acrítico, porque não questiona o que vê, atravessado pelos sentimentos e "certezas", falsas certezas. Nesse sentido o pesquisador transcende $o$ conhecimento do senso comum, aguçando o olhar científico, por desnaturalizar observações para poder construir conhecimento científico,

$\mathrm{O}$ afastamento do senso comum é o pensar sociologicamente, para o qual são necessários os processos de estranhamento e desnaturalização dos fenômenos sociais, princípios do ensino da Sociologia que podem ser 
aplicados em sala de aula. Na concepção Bergeriana, a perspectiva sociológica pode ser entendida como 'olhar por trás dos bastidores', propondo enxergar além das brechas das estruturas sociais, calibrando o olhar científico. O estranhamento é o primeiro passo para essa perspectiva, acima de tudo para o professor que pesquisa a própria prática.

Os autores Berger e Luckmann (1985) chamam os esquemas de classificação da realidade da vida cotidiana de tipificações. Nesses esquemas, para Berger e Luckmann, é que definimos como apreendemos as outras pessoas, seja pelo gênero, origem, profissão, idade, humor, entre outros aspectos. A partir dessas tipificações, são "estabelecidos os modos como 'lidamos' com" essas pessoas; "nos encontros face a face".

Hoje, esses encontros não se limitam apenas a esfera face a face. Estamos nos ambientando a classificar a realidade da vida cotidiana também por meio das relações que estabelecemos com as pessoas pelos meios tecnológicos, como a internet e pelo celular, sendo assim, faz-se necessário ajuste nas lentes teóricas investigativas.

\section{OLHAR CIENTÍFICO NA PES- QUISA EDUCACIONAL}

O termo construção aplicado à educação, de acordo Werneck (2006), pode ser entendido em dois sentidos:

-Como constituição do saber feita pelo estudioso, pelo cientista, pelo filósofo resultante da reflexão e da pesquisa sistemática que leva a novos conhecimentos. Nesse sentido, construíram-se e constroem-se através do tempo, os conteúdos da Física, da Química, da Biologia, da Medicina, [...]. O homem não "descobre" o conhecimento pronto na natureza, mas relaciona os dados dela recebidos constituindo os saberes. A ciência é o resultado desta elaboração mental, da reflexão, do estabelecimento de relações, da observação de causas, de consequências, de continuidades, de contiguidades, de oposições, [...]. Pode-se, portanto entender a construção do conhecimento como a constituição dos saberes que resulta da investigação filosófica-científica.

-Outra possibilidade de compreensão da ideia de "construção" do conhecimento refere-se apenas ao modo pelo qual cada um apreende a informação e aprende algum conteúdo. Neste caso, o sujeito não propriamente "constrói" o saber, somente apropria-se de um conhecimento já estabelecido. O conteúdo é passado pelo ensino, já pronto e definido embora sempre passível de modificações, e cada um vai apreendê-lo de modo semelhante mas não idêntico. Note-se, no entanto, que essa apreensão é feita de modo semelhante por todos, caso contrário não poderia ser entendido pela comunidade científica. Há, como mostra Husserl (1980), uma intersubjetividade entre os que dominam a mesma área do saber que atesta uma identidade na construção do conhecimento. (WERNECK, 2006, p.175-176).

São inúmeras as definições de ciência. Desde a mais sucinta, que a entende como o conhecimento sistematizado das causas do fenômeno, até as mais elaboradas, como a de Baremblitt (1978) que diz: "ser uma ciência um sistema de apropriação cognoscitiva do real e de transformação regulada desse real, a partir da definição que a teoria da ciência faz de seu objeto". (BAREMBLITT, 1978, p.16 apud WERNECK, 2006, p.177).

Werneck (2006, p.178) pontua que "há, evidentemente, uma pluralidade de discursos científicos e, inúmeras maneiras de se fazer ciência”. Várias áreas, desde as exatas até as humanas, convergem para análises, que conduziram o autor Kuhn, questionar dogmas consagrados, e enxergar o desenvolvimento da ciência não tanto como o acúmulo gradativo de novos dados gnosiológicos, e sim como um processo contraditório marcado pelas revoluções do pensamento científico.

Thomas S. Kuhn focalizou-se principalmente na análise da história da ciência, no qual aponta uma oposição entre duas compreensões da ciência: por um lado, na perspectiva formalista, a ciência é compreendida como uma atividade totalmente racional e controlada. Em contrapartida, na perspectiva historicista, a ciência é entendida como uma atividade concreta que ocorre no decorrer do tempo e que em cada período histórico apresenta características próprias, singulares e particulares.

A abordagem desse autor contribui ricamente para reflexões acerca do fazer científico ao considerar próprios da ciência os aspectos históricos e sociológicos que rodeiam a atividade científica, e não só os lógicos e empíricos, como defendia o modelo formalista. A grande novidade foi a inserção de uma reflexão sociológica sobre os cientistas e a formação de novos cientistas no cenário das ciências "duras" ou exatas e que depois se estende sobre as ciências humanas. A discussão do autor nos remete para uma conceptualização de ciência normal versus ciência revolucionária.

Para Kuhn, a ciência é um tipo de atividade altamente determinada que consiste em resolver problemas (como um quebra-cabeça) respaldado de uma unidade metodológica denominada paradigma. Este, apesar de sua suficiente abertura, delimita os problemas a serem resolvidos em determinado campo científico. É ele que estabelece o padrão de racionalidade aceito em uma comunidade científica sendo, portanto, o princípio fundante de uma ciência para a qual são preparados e treinados novos cientistas. 
A estrutura da concepção de Kuhn sobre ciência baseia-se na ideia de que o desenvolvimento típico (de uma disciplina científica, por exemplo) se dá ao longo do seguinte esquema (Figura 1):

Figura 1: Estrutura Kuhniana da ciência

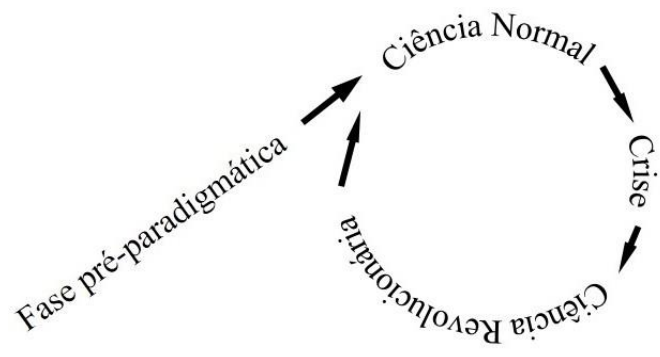

Fonte: Elaborado pelo autor

A fase pré-paradigmática é aquela na qual impera divergências entre os estudiosos, sobre quais fenômenos devem ser estudados, como os princípios teóricos se relacionam, quais métodos usar, quais técnicas e instrumentos podem ser utilizados, etc. Enquanto predomina um tal estado de "ideias" desestruturadas, a disciplina ainda não alcançou o estatuto de científica, ou seja, não constituiu uma ciência genuína. Kuhn (2011) salienta que, "o período pré-paradigmático, em particular, é regularmente marcado por debates frequentes e profundos a respeito de métodos, problemas e padrões de solução legítimos - embora esses debates sirvam mais para definir escolas do que para produzir um acordo". (KUHN, 2011, p.72-73).

Quando "em sua obra - hoje clássica - Matemática Elementar de um ponto de vista Superior (1908), o matemático alemão Felix Klein denuncia uma ruptura entre a matemática dos cursos universitários de formação de professores e a matemática da escola básica" (GIRALDO et al, 20018, p.2), ele marca a fase préparadigmática, do que posteriormente se constitui como ciência especializada, a Educação Matemática. Uma disciplina, ou área se torna uma ciência quando adquire um paradigma, ou conjunto de paradigmas, encerrando-se a fase pré-paradigmática e iniciando-se a fase de ciência normal.

Sendo assim, o paradigma caracteriza a ciência normal e o desafio para qualquer pessoa que está começando a fazer ciência é entender quais paradigmas estão postos para a definição científica naquele momento. E no campo das ciências humanas uma questão antecedente é se a ciências humanas é paradigmática.

$\mathrm{Na}$ área educacional, bem como em qualquer outro campo científico, um paradigma se configura como um elemento de verdade, espaço de verdade. É notório que há um paradoxo inerente ao paradigma, pois ao tempo que é fruto do desenvolvimento científico, ou seja, o desenvolvimento científico permite que se configure algumas "verdades"; o paradigma funciona como um limitador ao desenvolvimento cientifico exatamente por se configurar como um conjunto de problemas e soluções. A incrustação de um conjunto de paradigmas promove no campo da ciência, algo que parece ser contraditório ao desenvolvimento científico, a ortodoxia. O cientista pautado nessa linha de pensamento deixa de cumprir um princípio fundamental da ciência que é o da falseabilidade.

Em vez de verificar experiências empíricas que possam confirmar uma teoria, a comunidade científica deveria buscar fatos particulares que pudessem refutar a hipótese. A teoria que resistisse à refutação pela experiência seria considerada comprovada e nisso, a capacidade de ser refutada, consistiria sua superioridade em relação à metafísica.
Percebe-se que as pesquisas na área educacional, transcorrem dentro da Ciência Normal, onde elementos de "verdade" se acentuam. Normalmente, em um modelo educacional ocorrem anomalias ou contraexemplos que podem colocar em dúvida a validade de paradigmas. Se estes realmente se tornam insuficientes para submeter as anomalias à teoria - já que vista de outro ângulo elas podem se tornar um problema - inicia-se o período de crise que pode resultar no que Kuhn denomina de Ciência Revolucionária, que nada mais é do que a adoção de um outro paradigma, isto é, de visão de mundo.

Isto ocorre porque dentro de um paradigma há expectativas prévias que os cientistas devem corroborar. Por isso, os pesquisadores educacionais não buscam descobrir (como entendiam os pensadores do contexto de justificação) nada, mas simplesmente adequar teorias a fatos. Quando ocorre algo diferente deste processo, isso se deve a fatores subjetivos, como a incapacidade técnica do profissional, ou à inviabilidade técnica dos instrumentos, ou ainda à necessidade de real substituição do paradigma vigente. Principalmente nas ciências humanas, as investigações têm o intuito de dar significados, atribuir sentido, esse por sua vez, cria um cenário de ciência normal onde ocorre diálogo entre pesquisadores organizados da comunidade científica.

Por vez, professores pesquisadores se esbarram e devem driblar a ortodoxia existente no campo educacional e naturalmente ao defender suas teses de pesquisas terão que resistir ao princípio da falseabilidade da comunidade científica. $O$ fator temporalidade predomina, pois a revolução precisa de ser testada com muito trabalho rotineiro para atestação no campo psicótico, 
das configurações científicas, ou seja, dentro da Ciência Normal.

Percebe-se claramente que seria utopia um pesquisador educacional ou um professor-pesquisador fazer um projeto de ciência revolucionário, não que essa audácia seja completamente impossível, no entanto é infimamente provável. Um pesquisador com essa intenção, produzirá apenas ansiedade ao invés de conhecimento científico.

Embora a prática possa se dar por agente individualmente, a ciência é coletiva, se faz por interações sociais, sendo assim cada pesquisador deve estar conectado em uma rede de outros cientistas da área para que as crises existenciais na ciência normal possa resultar em ciência revolucionária.

Nesse sentido, o que muda do período da ciência normal para o período da ciência revolucionária é o paradigma, ou o conjunto de paradigmas que estrutura o pensamento dentro de determinado campo de conhecimento em determinado período. Essa transição até pode ocorrer de forma brusca, mas normalmente ela se dá de forma processual e contínua, gradativamente.

$\mathrm{Na}$ área educacional não devemos esperar acontecimento explosivo, por mais que os anseios do pesquisador sejam latentes, a temporalidade não será neutralizada. Ademais, a ciência se dá pelo princípio fundamental da "cumulatividade", no sentido de não desprezar todo e qualquer conhecimento já construído, nesse sentido um pesquisador em formação, deve se atentar e adentrar ao cenário de debate sobre o tema e objeto de pesquisa, (chamado de estado da arte) que se dá pelo conhecimento acumulado dentro da ciência normal, período no qual se acumulam descobertas, um período de estabilidade de opiniões a respeito de pontos fundamentais. Quando o paradigma é questionado, surge um mo- mento de crise; no entanto, o paradigma ainda não é abandonado. Os cientistas mobilizam seus esforços para resolver as anomalias. Chega-se a um ponto, porém, em que não é mais possível resolver tais anomalias e isso leva a uma revolução científica, momento no qual estabelece um novo paradigma. Esse paradigma não é superior ao anterior, apenas atende mais as necessidades do período histórico em que os cientistas estão inseridos. Por fim, o destino final da ciência revolucionária é se tornar ciência normal fechando um ciclo de construção de conhecimento científico.

Nesse processo de construção de conhecimento, nota-se que a figura do cientista polivalente, tal como como Galileu no século XIV, que é considerado um dos fundadores do método experimental e da ciência moderna, desapareu dando lugar ao pesquisador especialista

progressivamente setorizado. Atualmente até as áreas como matemática, física, biologia, geografia, etc, estão subdivididas em linha especificas de pesquisas, o que contribui para a produção de muito mais conhecimento e o avanço brusco da ciência. Por outro lado, gera uma visão linear, quando a ortodoxia inibe a contextualização entre os diferentes campos de pesquisas, ocorrendo uma secregação nos estudos teóricos das varias áreas.

No entanto, nenhuma investigação de fenômenos poderá ser levada a cabo com sucesso na ausência de um corpo de princípios teóricos e metodológicos que permitam seleção, avaliação e crítica do que se observa. Aqui se nota um dos principais enganos da concepção clássica de ciência, que imaginava ser possível fazer observações neutras. Nas concepções contemporâneas, reconhece-se que fatos e teorias estão em constante relação de interdependência, como que em "simbiose", os primeiros sustentando as últimas e estas contribuindo para a sua seleção, classificação, concatenação, predição e explicação. De posse de um corpo de princípios teóricos e regras metodológicas, o cientista não precisa a cada momento reconstruir os fundamentos de seu campo, começando de princípios básicos e justificando o significado e uso de cada conceito introduzido, assim como a relevância de cada fenômeno observado.

Segundo Werneck (2006), as variadas concepções filosóficas e epistemológicas, também sociológicas apontam para variados entendimentos sobre o processo de produção do saber, mas que, no entanto, algumas características são universalmente aceitas, uma delas é a impossibilidade de neutralidade axiológica. A autora ponderá que "não sendo possível a neutralidade e a imparcialicade na constituição dos saberes, há sempre uma interferência dos valores aceitos pelo sujeito na produção do conhecimento". (WERNECK, 2006, p. 179).

A neutralidade, na concepção weberiana (WEISS, 2014), é um distanciamento necessário que está na declaração de seus valores, no entanto é impossível um ser se despir por completo para então assumir o papel de cientista. Um professor jamais conseguirá deixar de ser o que é, para ser um pesquisador.

Outra característica comum é a provisoriedade dos saberes científicos. Não mais se aceita o conhecimento como um processo cumulativo, estático e acabado. Há, na ciência, uma revisão constante decorrente da possibilidade dos novos pontos de vista. O mesmo objeto pode ser 
analisando por diferentes lentes teóricas, o que leva à constatação da relatividade do conhecimento.

Nesse sentido, para um professor também ser um construtor de ciência, deve aguçar bem o olhar científico, concebendo claramente o ciclo na construção do conhecimento, inserindo-se no cenário de debates produzido, solidificando uma base teórica e metodológica que estrutararão uma arquitetura teóricoconceitual para inovadoras investigações científica na área educacional.

\section{RELAÇÃO ENTRE ENSINO E PESQUISA EDUCACIONAL}

As discussões sobre modelos de ensino corretos não são novas. Geralmente, o professor leciona numa instituição reconhecido como um profissional do ensino. Mas para tal, o ato de ensinar passou por estágios de evolução até se firmar como profissão docente.

O ofício de professor no Egito antigo estava ligado ao uso do discurso, objetivava desenvolver um ser eloquente. Na Grécia antiga, a educação enfatizava-se a formação do homem culto. Durante a Idade Média, a educação tinha como finalidade formação religiosa, clérigos precisavam de aprender a ler e escrever para catequizar os fiéis. A partir do século XVI, com consequências das reformas e contrarreformas religiosas fez com que o ensino fosse organizado coletivamente nas escolas, e esta se configurou como espaço específico para a educação.

$\mathrm{Na}$ contemporaneidade, cabe ao educador aprofundar o seu objeto de conhecimento, o ensino e a aprendizagem para melhor chegar ao seu objetivo. Durante esse período a ciên- cia foi se estruturando, e ponderando sobre o papel das instituições de ensino, Werneck (2006) alega que, "não se confundem o processo de fazer ciência com o de aprendê-la. Ensinar e aprender é função da escola. Fazer ciência é tarefa da comunidade científica. Um procedimento não se opõe ao outro. Ambos se completam, embora sejam distintos e com características próprias". (WERNECK, 2006, p.188).

Nesse sentido, a autora pontua que a escola básica deve apropriarse do conhecimento científico para disponibilizar ao estudantes, propiciando um contato com os "conhecimentos relativos à natureza, à vida social e com toda a produção científica, ao mesmo tempo em que o inicia na metodologia da ciência, despertando a capacidade crítica e preparando o futuro pesquisador". (WERNECK, 2006, p.189)

De acordo com Martins e Varani (2012), das potencialidades da articulação entre ensino e pesquisa na área da educação a serem mencionadas, estão as seguintes:

a) qualificação científica dos professores; b) qualificação científica dos pesquisadores em educação; c) melhoria da qualidade científica dos processos de ensinoaprendizagem desenvolvidos nas escolas; d) promoção das condições para que a comunidade escolar assuma o compromisso éticopolítico e social com a superação dos problemas educacionais e de outros presentes nas relações sociais; e) a assunção de uma formação que minimize a dicotomia entre quem pensa e quem faz, proporcionando ao professor outro lugar no processo do trabalho pedagógico, rompendo com a ação eminentemente tecnicista do docente. (MARTINS; VARANI, 2012, p.668-669).
Considerando o exercício profissional dos professores e dos pesquisadores da área da educação, é possível reconhecer que cada uma dessas modalidades de trabalho guarda certas especificidades que lhe são próprias. De um lado, há o exercício do processo de ensino-aprendizagem e, de outro, a reflexão, a pesquisa sobre ele como procedimentos aceitos por uma comunidade científica, o que pode ser realizado pelo mesmo profissional, o professor, que, agindo no ambiente escolar na qualidade de docente, pode ser, também, pesquisador.

Desse modo, a especificidade do trabalho do professor caracteriza-se pela promoção do ensino e a do pesquisador pela produção de conhecimento, o que "[...] exige conhecimentos, habilidades e atitudes diferentes [e] as tarefas delas decorrentes também têm graus de exigência e implicações diferentes" (ANDRÉ, 2006, p. 59). Ambos socializam o seus conhecimentos, no entanto enquanto o professor se restringe a espaço mais restritos, segundo Martins e Varani (2012):

Por sua vez, ao ser mencionado que o pesquisador socializa o conhecimento, é evidente que ele não procede, necessariamente, da mesma forma que o professor. A socialização dos conhecimentos por parte do pesquisador pode ser feita de variadas formas, mas as mais frequentes não utilizam processos de ensino, sobretudo o trabalho pedagógico. Amiúde, o conhecimento é socializado pelos pesquisadores por meio de bancas públicas de defesa de dissertações e teses, e mesmo por palestras, conferências, colóquios e outras formas de participação em eventos científicos, como também pela publicação de artigos e livros, por exemplo. (MARTINS; VARANI, 2012, p.654). 
Todavia, mesmo que se queira ver nessas particularidades do trabalho do profissional do ensino e do profissional da pesquisa em educação completa dissociação, separações cabais, isso não é possível por, basicamente, dois motivos: primeiro porque o professor, para ensinar, também precisa pesquisar, e, segundo, porque o pesquisador, ao ter produzido conhecimento, também o socializa de alguma forma:

Não há ensino sem pesquisa e pesquisa sem ensino. Esses que-fazeres se encontram um no corpo do outro. Enquanto ensino continuo buscando, reprocurando. Ensino porque busco, porque indaguei, porque indago e me indago. Pesquiso para constatar, constatando, intervenho, intervindo, educo e me educo. Pesquiso para conhecer e o que ainda não conheço e comunicar ou anunciar a novidade. (FREIRE, 1996, p. 16).

Uma associação explícita entre ensino e pesquisa não ocorreu até o século $\mathrm{XX}$, onde a pesquisa científica desenvolveu-se especialmente fora das instituições de ensino superior. Só no início do século XIX na Alemanha começou a integração entre ensino e pesquisa científica. $\mathrm{O}$ professor, além de conhecer o seu campo específico do saber, deveria pesquisar novas soluções para os problemas de sua área de conhecimento. $\mathrm{Na}$ atualidade, universalmente, tem-se que a pesquisa na universidade assim como o ensino, são considerados como parte da educação.

\section{CONSIDERAÇÕES FINAIS}

Ao finalizar essa pequena abordagem sobre o proceso de construção do conhecimento científico na pesquisa educacional faz-se algumas ponderações. A noção de "construção do conhecimento" é entendida como constituição de saberes aceitos em determinado tempo histórico com fins ao processo de aprendizagem do sujeito. Tanto o conhecimento do senso comum quanto o científico como modalidades diversas de abordagem do objeto, vão provocar um processo de aprendizagem ou de "construção" no sujeito.

A

construção

do

conhecimento não se dá de forma isolada, e sim por meio da interação social principalmente com a comunidade científica, com base na expectativa de realidade que é resultado de experiênicas da vida cotidiana. No caso da área educacional, conclui-se que há uma relação entre ensino e pesquisa e que o processo de ensino não se confunde com o da produção ciêntífica, mas deve estar estreitamente conectados.

O ensinar é incumbência da escola enquanto que fazer ciência é tarefa da comunidade científica, lembrando que um procedimento não se opõe ao outro. Ambos se completam embora sejam distintos e com características próprias. A construção dessa realidade se dá por interações face a face baseadas num conceito de tipificação.

O professor-pesquisador deve buscar exelência tanto na docência como na pesquisa. Considerando o ensino não apenas como a transmissão do já conhecido ao discente, mas como o processo que leva à capacidade de observação e reflexão crítica, preparando um possível pesquisador. $\mathrm{O}$ aprendizado da ciência leva à compreensão de sua gênese e do processo histórico que a justifica e explica o seu estatuto de cientificidade.
O bom ensino, que deve ocorrer não como um armazenamento de informações, mas como formação de referencias e desenvolvimento da capacidade de quetionar, vai ser fundamental para o produção científica.

É exigência da pesquisa científica, um arcabouço teórico, metodologia adequada, originalidade e dedicação, para se fazer bem a Ciência Normal com fins a ter bom discernimento, ou aguçar o olhar científico no sentido de quando for necessário, refutar um paradigma, substituindo-o por outro, revoluvionando a ciência.

\section{REFERÊNCIAS}

ANDRÉ, M. (Org.). O papel da pesquisa na formação e na prática dos professores. (Série Prática pedagógica). 5. ed. Campinas: Papirus, 2006.

BERGER, P. I.; LUCKMANN, T. Introdução. In: BERGER \& LUCKMANN. A Construção social da realidade: tratado de sociologia do conhecimento. Petrópolis: vozes, 1985.

Os

fundamentos do conhecimento na vida cotidiana. In: A construção social da realidade: tratado de sociologia do conhecimento. Petrópolis: vozes. 1985.

FREIRE, P. Pedagogia da autonomia: saberes necessários à prática educativa. São Paulo: Paz e Terra, 1996.

GIRALDO, V. A. et al. O laboratório de práticas matemáticas para o ensino. In: OLIVEIRA, A.; ORTIGÃO, M. I. (eds), Referências Teóricometodológicos de Grupos de Pesquisa em Educação Matemática. SBEM: São Paulo, 2018

KUHN, T. S. Introdução: um papel para a história. In: A estrutura das revoluções científicas. São Paulo: perspectiva, 2011 
A rota para a ciência

normal. In: A estrutura das revoluções científicas. São Paulo: perspectiva, 2011

A natureza da ciência

normal. In: A estrutura das revoluções científicas. São Paulo: perspectiva, 2011

MARTINS, M. F; VARANI, A. Professor e pesquisador: considerações sobre a problemática relação entre ensino e pesquisa. Rev. Diálogo Educ., Curitiba, v. 12, n. 37, p. 647 680, set./dez. 2012

SANTOS, E.R. Max Weber e as categorias básicas da sociologia compreensiva: ação e relação social. In: TESKE, O.(org.) Sociologia: textos e contextos. Canoas, ULBRA, 2005.

WEISS, R. Max weber e o problema dos valores: as justificativas para a neutralidade axiológicas. Revista de Sociologia e Política, v. 22, n. 49, p. 113-137, mar. 2014.

WERNECK, V. R. Sobre o processo de construção do conhecimento: o papel do ensino e da pesquisa. Avaliação e políticas públicas em Educação, Rio de Janeiro, v. 14, n.51, p.173196, abr./jun. 2006 